Gut and Liver, Vol. 10, No. 2, March 2016, pp. 204-211

\title{
Colorectal Cancer Screening: Stool DNA and Other Noninvasive Modalities
}

\author{
James R. Bailey*, Ashish Aggarwal ${ }^{*}{ }^{\dagger}$, and Thomas F. Imperiale*, ${ }^{*, \S}$ \\ ${ }^{*}$ Department of Medicine, Indiana University School of Medicine, ${ }^{\dagger}$ Community Health Network, ${ }^{\ddagger}$ Regenstrief Institute Inc. and Center of \\ Innovation, and ${ }^{s}$ Health Services Research and Development, Roudebush VA Medical Center, Indianapolis, IN, USA
}

Colorectal cancer screening dates to the discovery of precancerous adenomatous tissue. Screening modalities and guidelines directed at prevention and early detection have evolved and resulted in a significant decrease in the prevalence and mortality of colorectal cancer via direct visualization or using specific markers. Despite continued efforts and an overall reduction in deaths attributed to colorectal cancer over the last 25 years, colorectal cancer remains one of the most common causes of malignancy-associated deaths. In attempt to further reduce the prevalence of colorectal cancer and associated deaths, continued improvement in screening quality and adherence remains key. Noninvasive screening modalities are actively being explored. Identification of specific genetic alterations in the adenoma-cancer sequence allow for the study and development of noninvasive screening modalities beyond guaiac-based fecal occult blood testing which target specific alterations or a panel of alterations. The stool DNA test is the first noninvasive screening tool that targets both human hemoglobin and specific genetic alterations. In this review we discuss stool DNA and other commercially available noninvasive colorectal cancer screening modalities in addition to other targets which previously have been or are currently under study. (Gut Liver 2016;10:204 211)

Key Words: Colorectal cancer; Colorectal cancer screening; sDNA; Stool DNA

\section{INTRODUCTION}

Colorectal cancer (CRC) is the third most prevalent cancer both worldwide (1.23 million annual cases) and in the United States $\left(132,700\right.$ annual cases). ${ }^{1,2}$ While CRC mortality in the United States has been falling since 1985, attributed to both uptake of screening and advancements in treatment, an estimated
49,700 die annually, ${ }^{3}$ suggesting the need for continued screening efforts. The basis of CRC screening dates to the discovery of precancerous adenomatous tissue, ${ }^{4}$ which led to the understanding of development of CRC through the "adenoma-carcinoma" sequence rather than directly arising from the colorectal mucosa. ${ }^{5,6}$ Screening allows for early detection of CRC and removal of precancerous lesions, leading to reductions in cancer incidence and mortality. ${ }^{7,8}$

Despite strong evidence for CRC screening, ${ }^{9}$ adherence to screening in the United States remains a challenge as only 65\% of the eligible U.S. population is up-to-date with screening, while nearly $28 \%$ has never been screened. ${ }^{10}$ Challenges in increasing adherence have been attributed to patient and provider preferences, available resources, and healthcare infrastructure. ${ }^{11}$ Guidelines from several professional organizations, including the U.S. Preventive Services Task Force, Multi-Society Task Force, American College of Gastroenterology, and the National Comprehensive Cancer Network, provide both invasive and noninvasive options for CRC screening. While the American College of Gastroenterology considers colonoscopy to be preferred, other professional organizations recommend all options without preference. ${ }^{12-15}$ Despite these recommendations and patients' preference for noninvasive screening in several studies, providers are more likely to recommend colonoscopy and may not present other options. ${ }^{16-18}$ Patients who choose colonoscopy report doing so because of its superior single-application sensitivity, as reflected in statistics on its use, ${ }^{19}$ while those that do not choose it report many reasons including difficulty in scheduling, cost, and missed work time in addition to concerns of modesty, procedure discomfort, and bowel preparation. ${ }^{20}$ Colonoscopy also carries risk, such as bleeding, perforation, and cardiorespiratory complications. Although the risks are low, they are particularly relevant for patients with comorbid conditions $^{21}$ and may affect adherence. In an attempt to improve CRC screening and make available additional options without the

Correspondence to: James R. Bailey

Department of Medicine, Indiana University School of Medicine, 1120 West Michigan Street, Gatch Hall Room 626, Indianapolis, IN 46202, USA

Tel: +1-317-988-2522, Fax: +1-317-278-2650, E-mail: jarobail@iupui.edu

Received on August 27, 2015. Accepted on October 29, 2015.

pISSN 1976-2283 eISSN 2005-1212 http://dx.doi.org/10.5009/gnl15420

@) This is an Open Access article distributed under the terms of the Creative Commons Attribution Non-Commercial License (http://creativecommons.org/licenses/by-nc/4.0) which permits unrestricted non-commercial use, distribution, and reproduction in any medium, provided the original work is properly cited. 
risks and requirements of colonoscopy, noninvasive screening modalities are actively being explored.

In this review, noninvasive CRC screening modalities (Table 1, Fig. 1) will be discussed with a focus on stool DNA (sDNA). We will discuss the evolution of sDNA from proof of concept to its role in the current screening landscape. We will also briefly discuss other noninvasive screening tests, both established and in development

\section{GUAIAC-BASED FECAL OCCULT BLOOD TEST AND FECAL IMMUNOCHEMICAL TEST}

Noninvasive CRC screening in the United States started with annual guaiac-based fecal occult blood testing (gFOBT), which was first recommended by the U.S. Preventive Services Task Force in $1996,{ }^{22}$ based on evidence from population-based randomized trials. ${ }^{23-25}$ gFOBT works by indirectly identifying hemoglobin through a peroxidase reaction. Annual gFOBT reduces CRCs mortality by as much as 33\% over a 13-year followup and by 32\% in 30-year follow up. ${ }^{23,26}$ Despite its mortality reduction, gFOBT has several limitations. CRC sensitivity of a single round of gFOBT is reported as 30\% to 40\% indicating the need for annual testing which improves sensitivity to $90 \%$ over a 5-year period. ${ }^{27,28}$ Although annual testing has a high programmatic sensitivity, some of the sensitivity is due to false positive results from other causes of occult bleeding, which leads to serendipitous detection of neoplastic findings. ${ }^{29,30}$ In addition to the high false positive rate, gFOBT has the disadvantages of low sensitivity for advanced adenomas, the need for dietary and medication restrictions, and a requirement for the collection of three consecutive stool samples for testing. These limitations led to the development of the fecal immunochemical test (FIT)

Through the use of globin-specific antibodies, FIT allows improved stool-based detection of human hemoglobin. ${ }^{31}$ FIT exists as both a qualitative and quantitative test with several qualitative tests available in the United States. Given the number of tests and varying cutoff levels for a positive result, interpretation of these tests and comparisons is challenging. A recently published meta-analysis showed FIT sensitivity and specificity for CRC to be $71 \%$ and 94\%, among studies in which colonoscopy was the reference standard..$^{32}$ In a large study in Taiwan, FIT samples were obtained in 4,045 subjects the day prior to colonoscopy.

Colonoscopy-based findings were then compared to the previously obtained FIT with findings of FIT sensitivity for nonadvanced adenoma, advanced adenoma, and CRC of 10.6\%, $28.0 \%$, and $78.6 \% .^{33}$ Sensitivity varied based on location of leftsided versus right-sided lesions, with a decrease in the detection of more proximal lesions, although these findings have not held true in other studies. ${ }^{33,34}$ Large-scale, population-based trials comparing annual FIT to colonoscopy are in progress in Spain

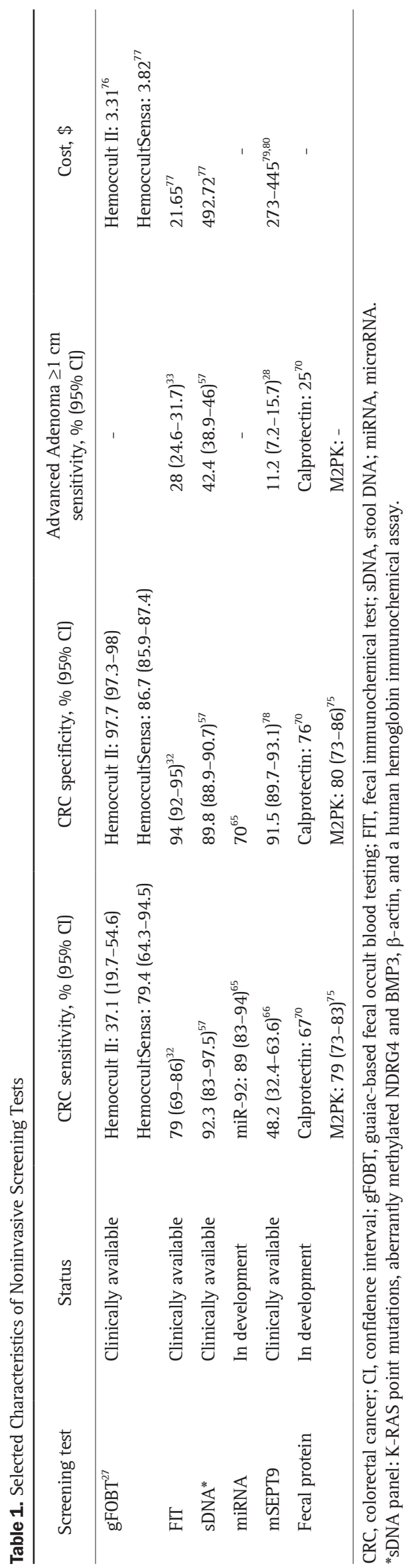




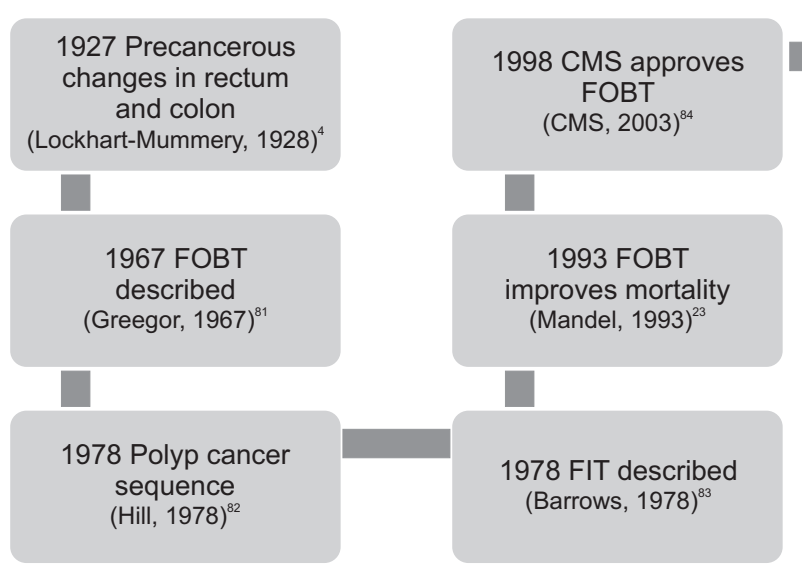

and the United States. ${ }^{35,36}$ Despite improved sensitivity in comparison to $\mathrm{gFOBT},{ }^{37}$ the need for only a single sample, and no dietary or medication restrictions, ${ }^{38,39}$ FIT has limitations, one of which is the decrease in sample reliability with prolongation of time from collection to analysis as positive FIT results decline from $8.7 \%$ at $1-4$ days to $6 \%$ at $\geq 5$ days, and $4.1 \%$ at $\geq 7$ days. $^{40}$ Other limitations include poor sensitivity for advanced adenomas $^{33}$ and an unclear optimal threshold for hemoglobin detection. $^{41}$

\section{STOOL DNA TESTING}

To further improve noninvasive screening, other methods have been and continue to be pursued. Development of CRC is associated with a series of progressive, cumulative mutations, including inactivation of tumor suppressor genes adenomatous polyposis coli (APC) and P53 and activation of the oncogene K-RAS. ${ }^{42,43}$ Identification of specific genetic alterations in CRC tumorigenesis and the knowledge that colonocytes are continuously shed set the stage for development of stool DNA (sDNA) as a screening test for CRC. ${ }^{44}$

The proof-of-concept study of sDNA for CRC screening by Ahlquist and colleagues involved 22 patients with known CRC, 11 with adenomas $\geq 1 \mathrm{~cm}$, and 28 with a negative colonoscopy who had stool samples analyzed with a panel of 15 point mutations of K-RAS, p-53, APC, and BAT-26, a microsatellite instability marker. The panel was 91\% sensitive for CRC and $82 \%$ sensitive for adenomas $\geq 1 \mathrm{~cm}$ with a specificity of 93\%; analyzable DNA was obtained from all samples. ${ }^{45}$ Additional studies further supported use of sDNA for CRC screening by showing that all mutations within stool samples were also present in CRC tissue samples, and that specific tumor markers were no longer detectable in stool samples following surgical resection of $\mathrm{CRC}^{46,47}$

Two screening population-based studies were conducted to evaluate first-generation sDNA test performance, both of which compared it to Hemoccult II (a gFOBT) and used colonoscopy as the reference standard. In one study, 2,507 average risk as-

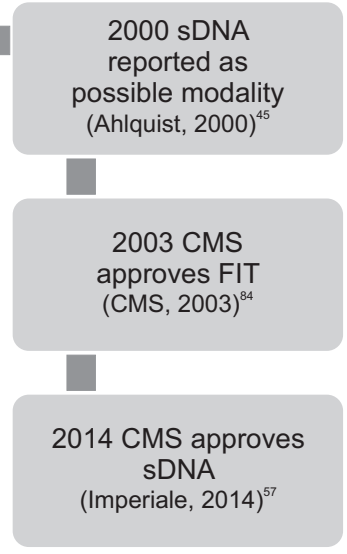

Fig. 1. Timeline of noninvasive colorectal cancer screening modalities. CMS, Centers for Medicare \& Medicaid Services; FOBT, fecal occult blood testing; sDNA, stool DNA; FIT, fecal immunochemical test. ymptomatic patients aged 50 or older were tested with a firstgeneration DNA panel, which included 21 point mutations of K-RAS, APC, BAT-26, and a DNA integrity assay. The sDNA panel had a CRC sensitivity of 52\% versus 13\% for Hemoccult II; sensitivity for high grade dysplastic adenomas was 32.5\% for sDNA versus 15\% for Hemoccult II, while respective CRC specificities were 94.4\% and 95.2\%. ${ }^{48}$ A second study using the same DNA panel in 4,482 average risk asymptomatic patients aged 50 or older showed a CRC sensitivity of 25\% versus 50\% for Hemoccult and 75\% for the more sensitive gFOBT HemoccultSensa. ${ }^{49}$ Due to poor performance of the DNA panel, a second DNA panel was used during the latter part of the study that included APC and K-RAS mutations and methylation of the vimentin gene. This second panel showed higher sensitivity for CRC (58\%) and in particular, for adenomas $\geq 1 \mathrm{~cm}$ (46\%) when compared with Hemoccult II (10\%) and HemoccultSensa (17\%). ${ }^{49}$ These findings led to sDNA inclusion in screening criteria by some organizations ${ }^{12}$ but the test's relatively low sensitivity and high cost resulted in only rare use in clinical practice. ${ }^{15}$

Several advances were made to improve both the marker panel and analytical methods to identify mutated DNA, resulting in greater sensitivity for the second generation sDNA tests. Long DNA degrades in storage, up to $75 \%$ in 1 day, ${ }^{50}$ indicating the need for human DNA preservation for improved detection. Addition of a stabilizing buffer to samples prevented bacterial degradation of human DNA. ${ }^{50}$ Identification of new markers $^{51,52}$ and improvements in the analytical process including automation $^{53}$ and development of advanced DNA stool extraction and mutant DNA detection techniques ${ }^{52,54,55}$ resulted in greater sensitivity, setting the stage for a new sDNA panel.

The second generation panel included four methylated genes (vimentin, NDRG4, BMP3, and TFPI2), a mutant form of KRAS, the $\alpha$-actin gene (to serve as a control for specimen quality), and a hemoglobin assay. This panel was tested on archived stool specimens. Target gene sequences were identified directly by hybridization with oligonucleotide probes. These probes were identified by Sera-Mag carboxylate modified beads which were then eluted out by use of a magnetic rack. Methylated markers 
were quantified using the Quantitative Allele-specific Real-time Target and Signal Amplification Assay (QuARTS), a highly sensitive polymerase based DNA amplification process that utilizes invasive cleavage-based signal amplification. ${ }^{56}$ A hemoglobin assay was added, which was not affected by stool storage. This new panel was initially tested on 252 patients with CRC, 133 with adenomas $\geq 1 \mathrm{~cm}$, and 293 with normal (i.e., "negative") colonoscopy results served as controls. sDNA testing was 85\% sensitive for CRC and 54\% sensitive for adenomas $\geq 1 \mathrm{~cm}$ with a specificity of $90 \% .^{52}$ Anatomical location of CRC and adenoma did not affect the panel's sensitivity. ${ }^{52}$ Further, sensitivity increased with adenoma size; as evidenced by sensitivity of 54\% for adenomas $\geq 1 \mathrm{~cm}, 63 \%$ for adenomas $>1 \mathrm{~cm}, 77 \%$ for adenomas $>2 \mathrm{~cm}, 86 \%$ for adenomas $>3 \mathrm{~cm}$, and 92\% for adenomas $>4 \mathrm{~cm}^{52}$ These findings provided impetus to test this new panel in a large screening trial using a similar marker panel and analytical process.

In the screening trial, 9,899 asymptomatic average risk individuals aged 50 to 84 years underwent testing with a multitarget sDNA panel and a comparator commercially-available FIT prior to undergoing screening colonoscopy, which served as the reference standard. ${ }^{57}$ The multitarget sDNA panel consisted of K-RAS point mutations, aberrantly methylated NDRG4 and BMP3, $\beta$-actin as a control indicator of DNA quantity, and a human hemoglobin immunochemical assay. The sDNA panel had a cancer sensitivity of $92.3 \%$ in comparison to $73.8 \%$ for FIT and a sensitivity of $42.4 \%$ for advanced precancerous polyps defined as advanced adenomas (adenomas with high grade dysplasia, with $>25 \%$ villous histologic features, or measuring $\geq 1 \mathrm{~cm}$ ) or sessile serrated polyp $\geq 1 \mathrm{~cm}$ versus $23.8 \%$ for FIT. The multitarget sDNA panel was significantly more sensitive than FIT although less specific (86.6\% for sDNA vs $94.9 \%$ for FIT). Subgroup analyses (Table 2) showed that sDNA sensitivity did not vary with CRC stage or location whereas FIT sensitivity was lower for proximal cancers. In addition, sDNA was more sensitive than FIT for higher risk advanced precancerous lesions. ${ }^{57}$ These favorable results led to approval of this multitarget sDNA panel for CRC screening by the Food and Drug Administration in August of 2014 and its current commercial availability for CRC screening.

As expected, additional challenges remain with the uptake of sDNA as a screening test. Although the FDA-recommended test interval is 3 years, there is no direct data from longitudinal studies to support appropriateness of this interval. Studies are in progress to address this important issue. Appropriate management of persons with a positive sDNA test but a "negative" colonoscopy is uncertain and requires clarification. Acceptance of sDNA by patients and providers in clinical practice is yet to be determined. Additional concerns include the cost-effectiveness of sDNA testing every 3 years versus other tests and strategies. Studies have suggested that while sDNA is more cost-effective than no CRC screening, it is less cost-effective when compared to other screening strategies including FOBT, FIT, and endoscopic strategies ${ }^{58-60}$ However, cost-effectiveness may not be unfavorable if sDNA can capture more of the eligible population and result in improved adherence to CRC screening. ${ }^{58}$ Early data shows that as of June 2015, approximately 36,000 patients have been screened with sDNA (data from Exact Sciences Corp.) since it became clinically available, ${ }^{61} 36 \%$ of whom were screened for the first time for CRC. There have been nearly 80,000 orders placed by 13,800 physicians with a $73 \%$ test completion rate (April to June 2015). ${ }^{61}$ Physician and patient selection of sDNA for CRC screening continues to increase as provider and patient education improves and insurance coverage for the test expands.

\section{OTHER NONINVASIVE MARKERS}

Other individual and panels of markers have been explored for their potential use as noninvasive screening tests, including microRNAs (miRNAs), plasma-based DNA, and stool proteins. We discuss these briefly in turn.

\section{MicroRNAs}

MicroRNAs (miRNAs) are short, endogenous, noncoding RNAs that regulate gene expression, thereby affecting various

Table 2. Subgroup Sensitivities for Stool DNA and Fecal Immunochemical Test

\begin{tabular}{lcc}
\hline & sDNA sensitivity, \% (95\% CI) & FIT sensitivity, \% (95\% CI) \\
\hline Stage I-III CRC & $93.3(83.8-98.2)$ & $72(60.3-83.9)$ \\
Any CRC & $92.3(83-97.5)$ & $73.8(61.5-84.0)$ \\
Proximal cancer* & $90(73.5-97.9)$ & $67(47.2-82.7)$ \\
Distal cancer* & $94(80.8-99.3)$ & $80(63.1-91.6)$ \\
CRC \& high grade dysplasia $^{*}$ & $83.7(75.1-90.2)$ & $63.5(53.5-72.7)$ \\
Advanced precancerous lesions $^{\dagger}$ & $42.4(38.9-46.0)$ & $23.8(20.8-27.0)$ \\
\hline
\end{tabular}

Adapted from Imperiale TF, et al. N Engl J Med 2014;370:1287-1297, with permission from Massachusetts Medical Society. ${ }^{57}$

sDNA, stool DNA; CI, confidence interval; FIT, fecal immunochemical test; CRC, colorectal cancer.

${ }^{*} 95 \%$ CIs calculated by the authors using exact method; ${ }^{\dagger}$ Advanced adenoma with high grade dysplasia, with $\geq 25 \%$ villous histologic features, or measuring $\geq 1 \mathrm{~cm}$ or a sessile serrated polyp $\geq 1 \mathrm{~cm}$. 
processes in tumorigenesis, including angiogenesis and metastasis. ${ }^{62}$ There has been great interest in looking at the expression of various miRNAs for detection of colorectal neoplasia. miR21 is the most studied oncogenic miRNA that is upregulated in colon cancer. Studies of its test characteristics have been inconsistent, with one study from Japan showing that the miR-21 expression was similar in colonocytes from healthy volunteers as compared to patients with CRC. ${ }^{63}$ Another study from 2012, however, showed that stool miR-21 expression was increased in CRC subjects as compared to healthy controls although expression was no different between subjects with adenomatous polyps and those without. ${ }^{64}$ Plasma levels of another miRNA, miR-92, were higher in subjects with CRC and the levels were significantly reduced after surgery in 10 CRC subjects. At a cutoff of 240 (relative expression in comparison to RNU6B snRNA), the sensitivity and specificity were $89 \%$ and $70 \%$, respectively, in discriminating CRC subjects from controls. ${ }^{65}$ Significant issues remain with respect to the optimal miRNA isolation technique, endogenous controls for serum based miRNAs, and the need to obtain test characteristics from a screening population.

\section{Plasma-based DNA markers}

Plasma-based DNA-markers, especially genes with aberrant methylation such as the SEPT9 gene, have been evaluated as potential screening targets for CRC and advanced adenomas. A multicenter prospective trial involving nearly 8,000 screening population subjects showed that the CRC sensitivity and specificity of circulating methylated SEPT9 DNA (mSEPT9) were 48\% and 91.5\%, respectively, while sensitivity for advanced adenomas was just $11 \% .{ }^{66}$ In a case-control study comparing the test characteristics of a multimarker test for sDNA and mSEPT9, mSEPT9 was found to have significantly lower sensitivity for detection of both CRC (60\%) and adenomas $>1 \mathrm{~cm}(14 \%)$ as compared with sDNA (87\% CRC sensitivity and 82\% adenoma sensitivity). ${ }^{67} \mathrm{~A}$ recent case-control study from China evaluating a plasma-based second generation mSEPT9 assay showed CRC sensitivity and specificity of $74.8 \%$ and $87.4 \%$, while advanced adenoma sensitivity was $27.4 \%$. In this study, mSEPT9 showed higher sensitivity than FIT for CRC but not for advanced adenomas. ${ }^{68}$ The lower sensitivity of plasma-based tests may be related to the requirement of biomarker release into the bloodstream via vascular invasion in tumorigenesis, which likely happens at a later stage as compared to exfoliation upon which stool-based tests are based. ${ }^{69}$ This observation may also explain lower sensitivity of plasma-based tests for detection of advanced adenomas as compared to CRC as vascular invasion occurs at a later stage in tumorigenesis. The place of mSEPT9 in the CRC screening landscape is uncertain at this time.

\section{Stool-based proteins}

Among stool-based proteins, fecal calprotectin and M2 pyruvate kinase (M2-PK, a cancer-related fecal protein) have been the two most studied fecal protein markers for CRC screening. In the Norwegian Colorectal Cancer Prevention trial involving 2,321 asymptomatic subjects, performance of calprotectin was inferior to FIT, with lower sensitivity for CRC (67\% vs 75\%), high risk adenoma (25\% vs 32\%), and lower specificity (76\% vs $90 \%)$. $^{70}$ Studies of fecal M2-PK have shown inconsistent results, ${ }^{71,72}$ with CRC sensitivity ranging from $68 \%{ }^{73}$ to $85 \%{ }^{74}$ among several studies with a cutoff value of $4 \mathrm{U} / \mathrm{mL}$. Results have varied based on the positive cutoff value used, ranging from a sensitivity of $92.1 \%$ and specificity of $29.7 \%$ for a cutoff of $1 \mathrm{U} / \mathrm{mL}$ to a sensitivity of $11.8 \%$ and specificity of $97.3 \%$ for a cutoff of $30 \mathrm{U} /$ $\mathrm{mL} .^{71}$ A recent meta-analysis of eight studies of M2-PK with a cutoff value of $4 \mathrm{U} / \mathrm{mL}$ showed a pooled CRC sensitivity, specificity and accuracy of 79\% (confidence interval [CI], 73\% to $83 \%$ ), $80 \%$ (CI, $73 \%$ to $86 \%$ ), and $85 \%$ (CI, 82\% to $88 \%$ ), suggesting that this marker may have potential as a screening test. ${ }^{75}$ However, further studies are needed in a screening population to accurately quantify its test characteristics.

\section{CONCLUSIONS}

The past 15 years have seen improvement in the uptake of CRC screening and reduction in CRC incidence and mortality in the United States. While colonoscopy is currently the dominant screening test in the United States, there is considerable interest in the development of accurate noninvasive screening tests, with notable improvements in stool-based tests in particular. Both FIT and sDNA provide viable noninvasive options to colonoscopy for average-risk persons. Both tests provide several advantages over colonoscopy, including ease of completion, low cost, and low risk. Ongoing research of sDNA will quantify its uptake, adherence, cost-effectiveness, and appropriateness of the 3-year testing interval. FIT and sDNA, should be included as options in discussions of CRC screening between provider and patient, with expectation of improved adherence to screening. Continued development of noninvasive tests, improved understanding of optimal screening intervals, and greater ability to risk stratify are likely to improve the efficiency of and adherence to CRC screening.

\section{CONFLICTS OF INTEREST}

James R. Bailey: Author has nothing to disclose.

Ashish Aggarwal: Author has nothing to disclose.

Thomas F. Imperiale: Grant support from Exact Sciences, Corp. to Indiana University.

\section{ACKNOWLEDGEMENTS}

Grant support: The Department of Medicine, Indiana University School of Medicine.

Author contributions: 
James R. Bailey: Literature review, manuscript development, composition.

Ashish Aggarwal: Literature review, manuscript development, composition.

Thomas F. Imperiale: Literature review, manuscript development, critical review.

\section{REFERENCES}

1. Ferlay J, Shin HR, Bray F, Forman D, Mathers C, Parkin DM. Estimates of worldwide burden of cancer in 2008: GLOBOCAN 2008. Int J Cancer 2010;127:2893-2917.

2. Siegel RL, Miller KD, Jemal A. Cancer statistics, 2015. CA Cancer J Clin 2015;65:5-29.

3. Edwards BK, Noone AM, Mariotto AB, et al. Annual Report to the Nation on the status of cancer, 1975-2010, featuring prevalence of comorbidity and impact on survival among persons with lung, colorectal, breast, or prostate cancer. Cancer 2014;120:1290-1314.

4. Lockhart-Mummery JP, Dukes C. The precancerous changes in the rectum and colon. Surg Gynecol Obstet 1928;36:591-596.

5. Fearon ER, Vogelstein B. A genetic model for colorectal tumorigenesis. Cell 1990;61:759-767.

6. Winawer SJ, Zauber AG, Ho MN, et al. Prevention of colorectal cancer by colonoscopic polypectomy. The National Polyp Study Workgroup. N Engl J Med 1993;329:1977-1981.

7. Brenner H, Chang-Claude J, Seiler CM, Rickert A, Hoffmeister M. Protection from colorectal cancer after colonoscopy: a populationbased, case-control study. Ann Intern Med 2011;154:22-30.

8. DeSantis CE, Lin CC, Mariotto AB, et al. Cancer treatment and survivorship statistics, 2014. CA Cancer J Clin 2014;64:252-271.

9. Schreuders EH, Ruco A, Rabeneck L, et al. Colorectal cancer screening: a global overview of existing programmes. Gut 2015; 64:1637-1649.

10. Centers for Disease Control and Prevention (CDC). Vital signs: colorectal cancer screening test use: United States, 2012. MMWR Morb Mortal Wkly Rep 2013;62:881-888.

11. Gupta S, Sussman DA, Doubeni CA, et al. Challenges and possible solutions to colorectal cancer screening for the underserved. J Natl Cancer Inst 2014;106:dju032.

12. Rex DK, Johnson DA, Anderson JC, et al. American College of Gastroenterology guidelines for colorectal cancer screening 2009 [corrected]. Am J Gastroenterol 2009;104:739-750.

13. Burt RW, Cannon JA, David DS, et al. Colorectal cancer screening. J Natl Compr Canc Netw 2013;11:1538-1575.

14. U.S. Preventive Services Task Force. Screening for colorectal cancer: U.S. Preventive Services Task Force recommendation statement. Ann Intern Med 2008;149:627-637.

15. Levin B, Lieberman DA, McFarland B, et al. Screening and surveillance for the early detection of colorectal cancer and adenomatous polyps, 2008: a joint guideline from the American Cancer Society, the US Multi-Society Task Force on Colorectal Cancer, and the American College of Radiology. Gastroenterology 2008;134:1570-
1595.

16. DeBourcy AC, Lichtenberger S, Felton S, Butterfield KT, Ahnen DJ, Denberg TD. Community-based preferences for stool cards versus colonoscopy in colorectal cancer screening. J Gen Intern Med 2008;23:169-174.

17. Shokar NK, Carlson CA, Weller SC. Informed decision making changes test preferences for colorectal cancer screening in a diverse population. Ann Fam Med 2010;8:141-150.

18. Inadomi JM, Vijan S, Janz NK, et al. Adherence to colorectal cancer screening: a randomized clinical trial of competing strategies. Arch Intern Med 2012;172:575-582.

19. Zapka J, Klabunde CN, Taplin S, Yuan G, Ransohoff D, Kobrin S. Screening colonoscopy in the US: attitudes and practices of primary care physicians. J Gen Intern Med 2012;27:1150-1158.

20. Denberg TD, Melhado TV, Coombes JM, et al. Predictors of nonadherence to screening colonoscopy. J Gen Intern Med 2005;20:989995.

21. Day LW, Kwon A, Inadomi JM, Walter LC, Somsouk M. Adverse events in older patients undergoing colonoscopy: a systematic review and meta-analysis. Gastrointest Endosc 2011;74:885-896.

22. U.S. Preventive Services Task Force. Guide to clinical preventive services: report of the U.S. Preventive Services Task Force. 2nd ed. Baltimore: Williams \& Wilkins, 1996.

23. Mandel JS, Bond JH, Church TR, et al. Reducing mortality from colorectal cancer by screening for fecal occult blood. Minnesota Colon Cancer Control Study. N Engl J Med 1993;328:1365-1371.

24. Libby G, Brewster DH, McClements PL, et al. The impact of population-based faecal occult blood test screening on colorectal cancer mortality: a matched cohort study. Br J Cancer 2012;107:255259.

25. Scholefield JH, Moss SM, Mangham CM, Whynes DK, Hardcastle JD. Nottingham trial of faecal occult blood testing for colorectal cancer: a 20-year follow-up. Gut 2012;61:1036-1040.

26. Shaukat A, Mongin SJ, Geisser MS, et al. Long-term mortality after screening for colorectal cancer. N Engl J Med 2013;369:11061114.

27. Allison JE, Tekawa IS, Ransom LJ, Adrain AL. A comparison of fecal occult-blood tests for colorectal-cancer screening. N Engl J Med 1996;334:155-159.

28. Church TR, Ederer F, Mandel JS. Fecal occult blood screening in the Minnesota study: sensitivity of the screening test. J Natl Cancer Inst 1997;89:1440-1448.

29. Lang CA, Ransohoff DF. Fecal occult blood screening for colorectal cancer: is mortality reduced by chance selection for screening colonoscopy? JAMA 1994;271:1011-1013.

30. Ederer F, Church TR, Mandel JS. Fecal occult blood screening in the Minnesota study: role of chance detection of lesions. J Natl Cancer Inst 1997;89:1423-1428.

31. Allison JE, Fraser CG, Halloran SP, Young GP. Population screening for colorectal cancer means getting FIT: the past, present, and future of colorectal cancer screening using the fecal immunochemical test for hemoglobin (FIT). Gut Liver 2014;8:117-130. 
32. Lee JK, Liles EG, Bent S, Levin TR, Corley DA. Accuracy of fecal immunochemical tests for colorectal cancer: systematic review and meta-analysis. Ann Intern Med 2014;160:171.

33. Chiu HM, Lee YC, $\mathrm{Tu} \mathrm{CH}$, et al. Association between early stage colon neoplasms and false-negative results from the fecal immunochemical test. Clin Gastroenterol Hepatol 2013;11:832-838.e2.

34. de Wijkerslooth TR, Stoop EM, Bossuyt PM, et al. Immunochemical fecal occult blood testing is equally sensitive for proximal and distal advanced neoplasia. Am J Gastroenterol 2012;107:15701578.

35. Quintero E, Castells A, Bujanda L, et al. Colonoscopy versus fecal immunochemical testing in colorectal-cancer screening. N Engl J Med 2012;366:697-706.

36. VA Office of Research and Development. Colonoscopy versus fecal immunochemical test in reducing mortality from colorectal cancer (CONFIRM). 2010 Nov 9 [last updated 2015 Jul 23; cited 2015 Jul 30]. In: ClinicalTrials.gov [Internet]. Bethesda: U.S. National Library of Medicine; 2000-. Available from: https://clinicaltrials. gov/ct2/show/NCT01239082.

37. Guittet L, Bouvier V, Mariotte N, et al. Comparison of a guaiac and an immunochemical faecal occult blood test for the detection of colonic lesions according to lesion type and location. Br J Cancer 2009;100:1230-1235.

38. Cole SR, Young GP. Effect of dietary restriction on participation in faecal occult blood test screening for colorectal cancer. Med J Aust 2001;175:195-198.

39. Cole SR, Young GP, Esterman A, Cadd B, Morcom J. A randomised trial of the impact of new faecal haemoglobin test technologies on population participation in screening for colorectal cancer. J Med Screen 2003;10:117-122.

40. van Rossum LG, van Rijn AF, van Oijen MG, et al. False negative fecal occult blood tests due to delayed sample return in colorectal cancer screening. Int J Cancer 2009;125:746-750.

41. Wong CK, Fedorak RN, Prosser CI, Stewart ME, van Zanten SV, Sadowski DC. The sensitivity and specificity of guaiac and immunochemical fecal occult blood tests for the detection of advanced colonic adenomas and cancer. Int J Colorectal Dis 2012;27:16571664.

42. Vogelstein B, Kinzler KW. The multistep nature of cancer. Trends Genet 1993;9:138-141.

43. Kinzler KW, Vogelstein B. Lessons from hereditary colorectal cancer. Cell 1996;87:159-170

44. Ahlquist DA, Harrington JJ, Burgart LJ, Roche PC. Morphometric analysis of the "mucocellular layer" overlying colorectal cancer and normal mucosa: relevance to exfoliation and stool screening. Hum Pathol 2000;31:51-57.

45. Ahlquist DA, Skoletsky JE, Boynton KA, et al. Colorectal cancer screening by detection of altered human DNA in stool: feasibility of a multitarget assay panel. Gastroenterology 2000;119:12191227.

46. Dong SM, Traverso G, Johnson C, et al. Detecting colorectal cancer in stool with the use of multiple genetic targets. J Natl Cancer
Inst 2001;93:858-865.

47. Syngal S, Stoffel E, Chung D, et al. Detection of stool DNA mutations before and after treatment of colorectal neoplasia. Cancer 2006;106:277-283.

48. Imperiale TF, Ransohoff DF, Itzkowitz SH, Turnbull BA, Ross ME; Colorectal Cancer Study Group. Fecal DNA versus fecal occult blood for colorectal-cancer screening in an average-risk population. N Engl J Med 2004;351:2704-2714.

49. Ahlquist DA, Sargent DJ, Loprinzi CL, et al. Stool DNA and occult blood testing for screen detection of colorectal neoplasia. Ann Intern Med 2008;149:441-450.

50. Zou H, Harrington JJ, Klatt KK, Ahlquist DA. A sensitive method to quantify human long DNA in stool: relevance to colorectal cancer screening. Cancer Epidemiol Biomarkers Prev 2006;15:11151119.

51. Itzkowitz S, Brand R, Jandorf L, et al. A simplified, noninvasive stool DNA test for colorectal cancer detection. Am J Gastroenterol 2008;103:2862-2870

52. Ahlquist DA, Zou H, Domanico M, et al. Next-generation stool DNA test accurately detects colorectal cancer and large adenomas. Gastroenterology 2012;142:248-256.

53. Lidgard GP, Domanico MJ, Bruinsma JJ, et al. Clinical performance of an automated stool DNA assay for detection of colorectal neoplasia. Clin Gastroenterol Hepatol 2013;11:1313-1318.

54. Diehl F, Schmidt K, Durkee KH, et al. Analysis of mutations in DNA isolated from plasma and stool of colorectal cancer patients. Gastroenterology 2008;135:489-498.

55. Zou H, Taylor WR, Harrington JJ, et al. High detection rates of colorectal neoplasia by stool DNA testing with a novel digital melt curve assay. Gastroenterology 2009;136:459-470.

56. Zou H, Allawi H, Cao X, et al. Quantification of methylated markers with a multiplex methylation-specific technology. Clin Chem 2012;58:375-383.

57. Imperiale TF, Ransohoff DF, Itzkowitz SH, et al. Multitarget stool DNA testing for colorectal-cancer screening. N Engl J Med 2014; 370:1287-1297.

58. Lansdorp-Vogelaar I, Kuntz KM, Knudsen AB, Wilschut JA, Zauber AG, van Ballegooijen M. Stool DNA testing to screen for colorectal cancer in the Medicare population: a cost-effectiveness analysis. Ann Intern Med 2010;153:368-377.

59. Skally M, Hanly P, Sharp L. Cost effectiveness of fecal DNA screening for colorectal cancer: a systematic review and quality appraisal of the literature. Appl Health Econ Health Policy 2013; 11:181-192.

60. Patel SS, Kilgore ML. Cost effectiveness of colorectal cancer screening strategies. Cancer Control 2015;22:248-258.

61. Exact Sciences. Exact Sciences provides update on strong launch trajectory of Cologuard [Internet]. Madison: Exact Sciences; 2015 [cited 2015 Jun 25]. Available from: http://www.exactsciences. com/about/latest-news/update-on-strong-launch-trajectory-ofcologuard $^{\circledR}$.

62. Yang W, Lee DY, Ben-David Y. The roles of microRNAs in tumori- 
genesis and angiogenesis. Int J Physiol Pathophysiol Pharmacol 2011;3:140-155.

63. Koga Y, Yasunaga M, Takahashi A, et al. MicroRNA expression profiling of exfoliated colonocytes isolated from feces for colorectal cancer screening. Cancer Prev Res (Phila) 2010;3:1435-1442.

64. Wu CW, Ng SS, Dong YJ, et al. Detection of miR-92a and miR-21 in stool samples as potential screening biomarkers for colorectal cancer and polyps. Gut 2012;61:739-745.

65. Ng EK, Chong WW, Jin H, et al. Differential expression of microRNAs in plasma of patients with colorectal cancer: a potential marker for colorectal cancer screening. Gut 2009;58:1375-1381.

66. Church TR, Wandell M, Lofton-Day C, et al. Prospective evaluation of methylated SEPT9 in plasma for detection of asymptomatic colorectal cancer. Gut 2014;63:317-325.

67. Ahlquist DA, Taylor WR, Mahoney DW, et al. The stool DNA test is more accurate than the plasma septin 9 test in detecting colorectal neoplasia. Clin Gastroenterol Hepatol 2012;10:272-277. e1.

68. Jin P, Kang Q, Wang X, et al. Performance of a second-generation methylated SEPT9 test in detecting colorectal neoplasm. J Gastroenterol Hepatol 2015;30:830-833.

69. Dickinson BT, Kisiel J, Ahlquist DA, Grady WM. Molecular markers for colorectal cancer screening. Gut 2015;64:1485-1494.

70. Hoff G, Grotmol T, Thiis-Evensen E, Bretthauer M, Gondal G, Vatn MH. Testing for faecal calprotectin (PhiCal) in the Norwegian Colorectal Cancer Prevention trial on flexible sigmoidoscopy screening: comparison with an immunochemical test for occult blood (FlexSure OBT). Gut 2004;53:1329-1333.

71. Shastri YM, Loitsch S, Hoepffner N, et al. Comparison of an established simple office-based immunological FOBT with fecal tumor pyruvate kinase type M2 (M2-PK) for colorectal cancer screening: prospective multicenter study. Am J Gastroenterol 2008;103:14961504.

72. Tonus C, Sellinger M, Koss K, Neupert G. Faecal pyruvate kinase isoenzyme type M2 for colorectal cancer screening: a meta-analysis. World J Gastroenterol 2012;18:4004-4011.

73. Haug U, Rothenbacher D, Wente MN, Seiler CM, Stegmaier C, Brenner H. Tumour M2-PK as a stool marker for colorectal cancer: comparative analysis in a large sample of unselected older adults vs colorectal cancer patients. Br J Cancer 2007;96:1329-1334.

74. Naumann M, Schaum B, Oremek GM, et al. Faecal pyruvate ki- nase type M2: a valid screening parameter for colorectal cancer? Preliminary results from a multicenter comparative study. Dtsch Med Wochenschr 2004;129(34-35):1806-1807.

75. Uppara M, Adaba F, Askari A, et al. A systematic review and meta-analysis of the diagnostic accuracy of pyruvate kinase M2 isoenzymatic assay in diagnosing colorectal cancer. World J Surg Oncol 2015;13:48.

76. Centers for Medicare \& Medicaid Services. Clinical laboratory fee schedule 2015 [Internet]. Baltimore: Centers for Medicare \& Medicaid Services; 2015 [cited 2015 Jul 30]. Available from: http:// www.cms.gov/Medicare/Medicare-Fee-for-Service-Payment/ClinicalLabFeeSched/clinlab.html.

77. Ahlquist DA. Multi-target stool DNA test: a new high bar for noninvasive screening. Dig Dis Sci 2015;60:623-633.

78. Church TR, Wandell M, Lofton-Day C, et al. Prospective evaluation of methylated SEPT9 in plasma for detection of asymptomatic colorectal cancer. Gut 2014;63:317-325.

79. Barton A. Blood test for colon cancer removes the 'ick' factor [Internet]. Vancouver: The Globe and Mail; 2010 [cited 2015 Jul 30]. Available from: http://www.theglobeandmail.com/life/healthand-fitness/blood-test-for-colon-cancer-removes-the-ick-factor/ article572600/.

80. StatLabs [Internet]. StatLabs; 2015 [cited 2015 Jul 30]. Available from: http://www.estatlabs.com/products/ColoVantage\%28methylated-Septin-9-biomarker-for-colon-cancer-screening\%29.html.81.

81. Greegor DH. Diagnosis of large-bowel cancer in the asymptomatic patient. JAMA 1967;201:943-945.

82. Hill MJ, Morson BC, Bussey HJ. Aetiology of adenoma: carcinoma sequence in large bowel. Lancet 1978;1:245-247.

83. Barrows GH, Burton RM, Jarrett DD, Russell GG, Alford MD, Songster CL. Immunochemical detection of human blood in feces. Am J Clin Pathol 1978;69:342-346.

84. Centers for Medicare \& Medicaid Services. Decision memo for screening immunoassay fecal-occult blood test (CAG-00180N) [Internet]. Baltimore: Centers for Medicare \& Medicaid Services; 2003 [cited 2015 Jul 30]. Available from: https://www.cms.gov/ medicare-coverage-database/details/nca-decision-memo.aspx?NC $\mathrm{AId}=87 \& \mathrm{TAId}=20 \& \mathrm{IsPopup}=\mathrm{y} \& \mathrm{bc}=\mathrm{AAAAAAAAAgAAAA} \% 3 \mathrm{D} \%$ 3D\&. 